\title{
Reorganization: The First Year
}

\section{Practice}

The second session of the Chichester Conference discussed how N.H.S. Reorganization was working in practice. The two working papers on "View from the Districts" and "Two Years on-Newcastle Revisited" are printed below, followed by the discussion, which was chaired by Dr. A.F. Smith, Assistant Editor, B.M.F. A glossary of N.H.S. terms was published at the end of the discussion in the first session (28 fune, p. 738).

\section{Working Papers}

\section{View From the Districts}

\author{
JANET LEWIS, S. WEINER
}

This report stems from some preliminary explorations we have made into the changes in the National Health Service after reorganization. We have discussed these with members of district management teams in five districts spread across the country and with some of the equivalent area and regional personnel. The districts were chosen to cover a wide range of circumstances (single and multidistrict, urban and rural, rich and poor, teaching and non-teaching), though we could not do more than skim the surface of what is happening.

The first year of reorganization has been a special one in any case, not just because of reorganization, but because the rate of inflation and industrial unrest have affected the Service. Even so, general patterns have emerged and it is these which we wish to discuss, though obviously our statements do not apply to all individuals or all places and there will be many variations throughout the country. Thus we have made bold generalizations rather than hedging our discussion with "in some cases" or "it seems that."

\section{Boundary Questions}

The boundaries of the three tiers were chosen to meet different criteria. The regions and districts are based on the Health Service and hospital while the areas coincide with local authority boundaries. This lack of a compatible progression makes aggregation from one tier to the next difficult. In ideal circumstances groups of districts, based on hospital catchment areas, would not be co-ordinated and planned within areas coterminous with local authorities, but areas chosen on health planning grounds. The definition of district boundaries themselves was not easy. In many places, particularly London, it was impossible to measure patient flow, or there were different movements for different services so that hospital catchment areas could not be neatly incorporated in one district. Compromises were therefore made, which resulted in not all districts being a "viable unit for the planning, organization and provision of comprehensive health care" (Department of Health Circular H.R.C.(73)4)

The key decisions about allocation of districts were taken by the joint liaison committees, whose members were representatives of the old health authorities. Thus while the definition of the district was one which was vital to the power and resources of the new service, the people who were to run this did not participate in its inception. The members of joint liaison committees came from the hospital service or local government and each group tended to push their own population and purpose rather than choosing "the most appropriate organizational unit within which to plan for and provide co-ordinated primary and secondary health care" (Department of Health Circular H.R.C.(73)4). In London, the hospitals seem to have won especially so that what the hospitals wanted as their catchment area became the natural district for everything.

\section{The District Team}

In almost all cases the six members of the district management team (administrator, community physician, finance officer, nurse, and two clinicians) are making a genuine effort to make the consensus decision-making system work. The first year has 
been a time of testing out reactions and getting to know each other and in some cases "matters are not important enough to disagree on yet." Nevertheless, where there has been conflict there has still been a strong influence to maintain the consensus so that the decision should not be made by higher authority: "to admit lack of decision is to admit defeat." The result is that any serious difference of opinion is concealed rather than made visible to the area team of officers or the area health authority. Controversial issues tend to be put off to await resolution and are therefore delayed rather than referred for decision elsewhere. This consensus at any cost seems to be endemic throughout the system (unit management team to D.M.T., D.M.T. to A.T.O., A.T.O. to A.H.A.).

Within the consensus pattern each individual member of the team still has considerable autonomy and there is much bargaining on behalf of the interests represented by each member. Similarly, for reasons of personality and position some team members are considerably more influential than others, and some natural alignments are forming. In some teams this is the two clinicians versus the four officers; elsewhere it is the two clinicians plus the administrator, or the consultant member and the administrator versus the rest.

\section{Districts Within Areas}

The boundaries between the work of the district management team and the area team officers are proving difficult to define in practice. In the first year in any case individuals would have been feeling their way, but what is happening is more than this: the districts are fighting very hard and with considerable success to be individual levels in their own right and in all cases we have seen they are the effective operating level. As such the districts are in a position of strength in relation to the A.T.O. who depend on them for information and have to rely on them to implement the decisions taken by the A.H.A. In the absence of the planning cycle, and with money being scarce, the work which the members of the A.T.O. see as monitoring two or three districts is being perceived by the districts as attempted control and is being fiercely resisted.

In this first year there has been only one job, that of running the Service, but in multidistrict areas there have been what are effectively two operating levels of district and area competing for this job. The situation may now be stabilizing but the areadistrict relationship has been a source of continuing conflict in every place we have visited-except, of course, in single district areas where the difficulties expressed elsewhere are noticeably absent.

"The A.H.A. will be a small body selected for its capability."1 The area health authority is important as a public forum and has a symbolic function. Nevertheless, we have found no authority where the members (meeting in full session for only a couple of hours a month) are actively involved and knowledgeable about what is happening. The officers think that they provide a mass of information to the authority, whose members, owing to their lack of knowledge, cannot disagree with them. The main exception to the lack of involvement are those A.H.A. members who represent the health professions, as they bring knowledge of the system from outside through their professional roles. Nevertheless, great reliance has to be put by the authority on to its chairman and officers and this is more than mere delegation.

The chairmen receive part-time salaries and were picked for their interest and involvement in the Health Service. It is through their relationship with the A.H.A. and its chairman that the A.T.O. show that they have a different status from the D.M.T.s. The A.H.A.s offices are shared with the A.T.O. and the chairmen inevitably develop closer contact with the area officers than the district. There are few candid and direct contacts between teams and the A.H.A. members and it is therefore difficult district for the latter to avoid being "captured" by the area administrator or the A.T.O. The districts are responsible to the A.H.A. for the functions delegated to them, ${ }^{2}$ but the A.T.O.s powers to review district plans, together with their physical proximity to the A.H.A., results in the districts' views being effectively screened by the A.T.O.

\section{Area Team and Relationships With the Region}

The four officers without the two clinicians can work together more informally than a team of six. The same kind of consensus pattern appears to be operating within the A.T.O. as with the D.M.T. except that it is sometimes the chairmen and usually the area health authority who are not informed about disagreements.

Areas feel themselves fenced in by some regions much as the districts feel fenced in by the areas. The old regional hospital boards dealt directly with hospital management committees and, as the carry-over of senior regional officers has been quite strong, "they treat us like an H.M.C." is a constant refrain. Thus some areas have found that the region has not allowed them the autonomy appropriate to a supposed planning authority. The regions appear to be maintaining tight financial control and their traditional power over capital spending. Some regions are also still involving themselves in detailed matters such as the creation of minor additional posts.

\section{Professional Roles}

Members of a team are also, of course, members of different professions, and these professional groups are also beginning to develop distinct characteristics within the system. In single district areas the tensions between members of the same professional groups in different tiers are absent. The distinct characteristics remain the same, but in our subsequent discussion the job content of officers in single district areas may be taken to be a combination of those at area and district in multidistrict areas.

Both area and district administrators have usually come from the hospital service. In this and many of the other roles the area staff seem to be implicitly seeking to reinstate prior hierarchical (line) relationships. District administrators have tried to resist this, especially where both they and their area counterparts were previously group secretaries at the same level. This problem is particularly acute in teaching districts where many of the house governors have been directly transformed into district administrators with a prereorganization legacy of having no superior except the D.H.S.S. itself.

In their co-ordinating role the administrators tend to form a strong communication/influence channel for the team, both at area and district. Area and district administrators meet regularly, when many inter-tier disputes are sorted out. Similarly area administrators meet on a regional basis and look to the regional administrator to speak for his team on many issues. In his role as secretary to the A.H.A. the area administrator has an active role and is often seen as the hub of the communication network.

Treasurers are one of several formerly subordinate groups who are now nominally equal, but are only gradually concerning themselves with broader issues. In several cases the attempt to reinstate a hierarchical relationship between district and area has met with more success than with other team members. This is partially a matter of the politics of technology since area treasurers have made a strong case for centralized payrolls, billing, and supplies. Effective functional budgeting might make a radical difference to inter-tier relationships in strengthening the hand of the district finance officer, and is also likely to alter intra-tier relationships by bringing the D.F.O. more centrally into the planning and management functions. Nevertheless, functional budgeting is several years away in most places.

Area medical officers and district community physicians have new jobs radically different from most of their previous experience and training and are only slowly beginning to find their feet. Not surprisingly, the highest level of conflict has shown up in the co-ordination of these roles. Most of the occupants of both these posts are drawn from local authorities and are ex-medical officers of health or their deputies whose experience is of quite independent chief officer status within a small hierarchical organization. They are now expected to carry out a broad non-executive planning role especially through the co-ordination of hospital and community services. Nevertheless, an M.O.H. background is usually seen as not very prestigious by hospital- 
oriented team members-especially clinicians who often see M.O.H.s as "failed doctors." Their chance of being effective in the hospital setting is therefore small and they similarly have little possibility of claiming special medical expertise at the district level on a team with two practising clinicians. M.O.H.s also had rather low status as administrators and therefore now find it difficult to compete on an equal basis with the ex-hospital administrators for the co-ordinating role. Nevertheless, there is considerable variation in the extent to which community physicians have escaped identification with the community services for which they or their predecessors were responsible in the past.

The D.C.P.'s particular role involves co-ordinating health care planning teams, but these have mostly been slow to get off the ground. Nevertheless, the involvement of D.C.P.s in the extensive problems of setting up these teams has left them little time to participate in team management of the hospital service. In some places H.C.P.T.s are thought to be already contributing to the problem-solving activities of the D.M.T., but in others are perceived as "something to keep the D.C.P. occupied" rather than as a radical means of altering the distribution of resources.

Area medical officers are having great difficulty differentiating their role from that of the D.C.P. and this has been a source of frustration. The A.M.O.s have been forced to assert that some items are more appropriately planned on an area-wide rather than district-wide basis and have tried to exert their own influence on H.C.P.T.s, especially in terms of topics, membership, and terms of reference. The districts have naturally been resisting these suggestions and directives and there have been similar conflicts over the planning and co-ordination of health centre programmes.

Everyone is quite happy to devolve nurse management to the nurses and in turn the nurses, particularly at the district level, are only rarely allowing themselves or being allowed to involve themselves in broader team issues. On the basis of the limited information we have, they seem to be devoting their time to creating management structures and to the problems of integrating the hospital-community split. Area nurses have not yet found a clear role for themselves and are involving themselves in "co-ordination," with all its implications for line management. Nurses in the districts are strongly resisting this implicit hierarchical relationship.

\section{Professional Strategies}

In uncertain times when new roles are being evolved and tested out, individuals have to develop strategies to "manage" and maintain their positions. The strategies we have so far discerned in area-district relationships confirm the earlier suggestion that there is at present only one job to be done-that of managing the Service. Strategies include, in circumstances where strong district team members have taken a very independent line, their area counterparts deciding they have no real job. At the other extreme some area treasurers have defined it as all their job and have attempted to use the district staff as their agents. In between where there is no settled division of "the role" there is continuing conflict over who is responsible for what.

"The simplest way to face the future is just to do what you did before." Individuals have come to new jobs from within the old N.H.S. and therefore bring with them a legacy of past experiences, tried ways of doing things, and a communication network. When in doubt these old patterns are brought into play by almost everyone. (Incidentally this is another reason why area jobs may be difficult to structure as no one has any past experience of the co-ordination required and therefore the behaviour they fall back on is likely to be inappropriate).

In addition, among more assertive team members new ways of exerting influence are being developed. The functions of team co-ordinator/chairman can provide this opportunity, or the "honest broker" role, where a D.C.P. or treasurer might advocate his own views in the format of disinterested technical advice.

The new structure involves a host of new advisory committees as well as direct representation by clinicians on the district team. Not all the committees are as alive in fact as they are on paper, and much depends on the legacy of medical politics in the local community. The G.P. local medical committees were often well organized bodies and have been reconstructed in much the same way at area level, usually with district subcommittees. Where Cogwheel schemes existed hospital medical work was previously co-ordinated through the medical executive committees. Nevertheless, not all places had a well established and fully accepted Cogwheel structure and therefore lacked a co-ordinated hospital viewpoint on the medical side.

The district medical committee, consisting of representatives of both G.P.s and hospital doctors, is meant to co-ordinate "the medical aspects of health care throughout the district". "In fact, it seems to be serving as an electoral college for the two professional members on the D.M.T. and has little role of its own. Most issues needing professional advice are still dealt with directly by the medical executive committee (or consultant group if no Cogwheel structure exists) or the local G.P. medical committee. Area medical advisory committees, since they do not elect members to the A.T.O., seem to have no clear function and are generally bypassed.

Consultants are inevitably very conversant with the professional operations of the hospital service and are often perceived by nondoctors to possess uniquely significant medical knowledge. In addition, the hospital is a complex political community and where a consultant is known to speak for his colleagues his status gives him a potent role in D.M.T. discussions. Where the consultant community is relatively unorganized, either owing to the lack of a Cogwheel arrangement or where this does not provide a focus of medical opinion, then the consultant member of the D.M.T. plays a less significant part.

The position of the G.P. on the D.M.T. is more ambiguous and open to more variation. As independent contractors G.P.s do not lways have the same "community of interest" as hospital doctors as they are not competing with each other in the same way for resources. Equally, much of the G.P. service remains independent of the D.M.T. decisions and therefore the G.P. member of the team does not have a great deal to gain from the team for his colleagues. The G.P.'s influence seems to depend in part on his involvement in and knowledge of hospital and community services and his use of his "independent" status.

In the course of the year the implicit tensions between the representative role and the management role of the clinician members have begun to come to the surface (the professional sanctions this winter have had a part to play in this). Some clinicians have had to decide, in each of the forums in which they participate, which side they are actually on and for whom they speak. Interestingly, those nurses at the district level, who see part of their role as representing "their" staff, have also felt this conflict.

\section{Impacts At The End Of The First Year}

Any major reshuffle involves considerable confusion and relearning and after the first year the dust is only just beginning to settle. In some places, particularly London, there has been considerable change round in posts and therefore it has taken many months to learn the job and come to terms with established programmes.

The major task of appointing personnel also started late, with area officers being appointed in only November/December 1974, four or five months before the appointed day. Many district team members did not take office until 1 April 1975 or later, while the essential second and third level staff posts at both area and district are still being filled at present. In addition, the creation of "new" jobs such as full-time personnel experts, coupled with restrictions on recruitment outside the N.H.S., has led to complaints from staff in post about the "quality" of some applicants.

The chronic crisis state of the N.H.S. in the past year has given more than usual justification to the claim that "we are just trying to keep things going." The negligible changes in the first year should serve to point to the difficulties that are likely to occur in later years in introducing change, particularly as precedents accumulate and the early, fluid relationships begin to harden.

\section{Community Health Services}

For the most part the hoped for priority for community services within the N.H.S. has not taken place. The major rethinking needed to shift resources from one sector to another has only just begun and with budgets as tight and confused as they have been this year there has been little room for manoeuvre. Most members 
of the district and area teams have come from hospitals and it has taken them most of the year to find out what community services are available in their districts. Thus $90 \%$ of the districts' budget remains with the hospital service for the present.

As they find out about the rest of the N.H.S. some hospital people are concluding that resources should go to hospitals rather than local clinics anyway. Alternatively, now that all three branches of the Service are theoretically being administered by one body, the continued separation into three parts is considered to make no sense. The services provided by local clinics and the community staff could be absorbed by the other arms of the Service and be based either in hospitals or with G.P.s.

The financial control of the administrative side of the family practitioner services has now become a matter for the A.H.A. rather than the D.H.S.S. Apart from this there is little difference between the work of the family practitioner committee and the old executive council. There have been few formal contacts between F.P.C.s and A.H.A.s and, though contact at officer level may be close, this in part depends on the individuals having known each other personally in the old system. G.P.s and the other practitioners continue, as agreed, in their independent contractor position and the arrangements for negotiating health centres and alterations in practice conditions with them continue as before. Any major redistribution of resources or services among hospitals, practitioners, and the old community services lie in the future.

The key to shifting the burden of caring for long-stay patients from relatively expensive hospital care to the community has always been the social services. These are still organized by local authorities and so far they are no closer to the Health Service than before reorganization. Joint Consultative Committees, consisting of members of local authorities and area health authorities-whose job it is to advise on collaborative activities -are only just being set up. Few people in the Health Service think that these committees will be able to achieve much through joint planning as the pressure will be mainly on the local authorities to do more. Equally, these committees can do little about day-to-day collaboration as they are at the wrong level in the N.H.S. Operationally the district should have the links with social services and yet there are no formal mechanisms for this, and up to now informal contact has depended on the personalities involved. An additional problem is that social service "districts" do not match those in the Health Service and perhaps more important still is the fact that social services are operating under budgets as constrained as the Health Service.

\section{Planning}

A major justification put forward for the structure of the new Service was that it would allow opportunities for broadly based planning to take place. The hope was that such planning would bring about significant changes in the way resources are spent. In fact, the beginning of the D.H.S.S.'s own planning cycle is still a year away and will take some time to develop. Until planning not only occurs but has a visible impact then the elaborate staff structure at each level will seem unnecessarily unwieldy to many within the Service and to some of us without.

\footnotetext{
${ }^{1}$ Management Arrangements for the Reorganized National Health Service, para. 2. 11. London, H.M.S.O., 1971.

2 Management Arrangements for the Reorganized National Health Service, para. 2. 15. London, H.M.S.O., 1971.

3 Management Arrangements for the Reorganized National Health Service, para. 4. 7. London, H.M.S.O., 1971.
}

Centre for Studies in Social Policy, London

JANET LEWIS, Fellow

S. WEINER, Visitin $;$ Fellow

\section{Two Years On-Newcastle Revisited}

\section{W. F. WHIMSTER}

Two years ago the B.M. F. published a series of articles ${ }^{1-6}$ about how local medical, nursing, and administration staff expected N.H.S. reorganization to affect Newcastle-upon-Tyne and Gateshead. For this symposium I went and talked to two of the people who had been concerned in those articles-Dr. Andrew Smith, a general practitioner in the Gateshead single-district area, and Dr. Bryan Shaw, then deputy M.O.H. for Newcastle and now Area Medical Officer (A.M.O.) for North Tyneside (also a single-district area). Two other doctors also took part in the discussion: Professor John Walton, Dean of the Faculty of Medicine in Newcastle University, and Dr. David Henley, A.M.O. in Gateshead. In this paper I have briefly summarized their contributions from their three single district areas (including a teaching area) under somewhat arbitrary headings.

\section{M.O.H. to A.M.O.}

Though working either in or near their old environments, the former M.O.H.s find themselves doing completely different jobs. But a year later they still spend time directing their old friends (especially in the local authorities) to people who are now doing bits of their old jobs. And, though the main posts in the reorganized N.H.S. have now been filled, the supporting staff in nursing administration and finance are still being appointed. People are still uncertain whether they will get substantive jobs in the new service and morale is low. It is not true that many new posts have been created-but experienced people have retired early, many people have changed jobs, and others have been promoted perhaps too quickly. Gateshead is fortunate in that the central organization of the integrated service is all in one building.

The new A.M.O.s are having to spend time finding out about the hospital side of the service, and have spent little time so far on community services apart from health centres (for which the D.H.S.S. is providing cash). They have found that the plans for their district general hospitals have been delayed-an unhappy result of the coincident economic blizzard. In the teaching area, too, many plans have gone back into the melting pot-particularly the promise by the D.H.S.S. that all the hospitals in the university hospitals group (reorganized three years before reorganization to include all the Newcastle hospitals under the regional board) should be brought up to teaching hospital standard. The new Freeman Road district general hospital was an integral part of the old plan, but has not been financed as such.

\section{Team Working}

The A.M.O.s are, of course, key members of their area management teams (the D.M.T.s of single-district areas). No individual member dominated their A.M.T.s because these have emerged as teams, and their regular meetings have been particularly helpful while "working to contract" and other industrial actions have been going on. The A.M.T.s have been in no hurry to set up Health Care Planning Teams-only two have been established in North Tyneside, for family planning and geriatrics, and three teams in Gateshead-because they say that they do not want to raise expectations for schemes which cannot be paid for. Though the A.M.T.s can visit all N.H.S. establishments, including health centres (but not G.P. premises-which are covered by reference to the family practitioner committees), there have been no complaints that they are "snooping." The G.P. member of the A.M.T., who was elected by the local medical committee in North Tyneside, is a well-respected doctor who probably spends two to three sessions a week on the team as well as attending the A.M.C. and A.H.A. and taking part in informal discussions. But one hospital consultant, a 